\title{
Incidence and prognostic factors of chronic pain after isolated musculoskeletal extremity injury
}

\author{
J.G.J. Pierik', M.J. IJzerman ${ }^{1}$, M.I. Gaakeer ${ }^{2}$, M.M.R. Vollenbroek-Hutten ${ }^{3}$, A.B. van Vugt ${ }^{4}$, C.J.M. Doggen ${ }^{1}$ \\ 1 Health Technology \& Services Research, MIRA Institute for Biomedical Technology and Technical Medicine, University of Twente, Enschede, The \\ Netherlands \\ 2 Emergency Department, Admiraal De Ruyter Ziekenhuis, Goes, The Netherlands \\ 3 Biomedical Signals and Systems, MIRA Institute for Biomedical Technology and Technical Medicine, University of Twente, Enschede, The \\ Netherlands \\ 4 Emergency Department and Department of Surgery, Medisch Spectrum Twente, Enschede, The Netherlands
}

\author{
Correspondence \\ Jorien G.J. Pierik \\ E-mail: j.g.j.pierik@utwente.nl
}

Funding sources

None.

Conflict of interest

None declared.

Accepted for publication

27 August 2015

doi:10.1002/ejp.796

\begin{abstract}
Background: Chronic pain in patients is usually related to an episode of pain following acute injury, emphasizing the need to prevent progression from acute to chronic pain. Multiple factors in the acute phase might be responsible for perpetuating the pain. The presentation of patients at the emergency department (ED) presents a prime opportunity to identify patients at high risk for chronic pain and to start appropriate treatment.

Methods: The PROTACT study is a prospective follow-up study aiming to estimate the incidence and prognostic factors responsible for the development of chronic pain after musculoskeletal injury. Data including sociodemographic, pain, clinical, injury- or treatment-related and psychological factors of 435 patients were collected from registries and questionnaires at ED visit, 6-week, 3- and 6-month follow-up.

Results: At 6 months post-injury, $43.9 \%$ of the patients had some degree of pain (Numeric Rating Scale (NRS) $\geq 1$ ) and $10.1 \%$ had chronic pain (NRS $\geq 4$ ). Patients aged over 40 years, in poor physical health, with pre-injury chronic pain, pain catastrophizing, high urgency level and severe pain at discharge were found to be at high risk for chronic pain.

Conclusions: Two prognostic factors, severe pain at discharge and pain catastrophizing, are potentially modifiable. The implementation of a pain protocol in the ED and the use of cognitive-behavioural techniques involving reducing catastrophizing might be useful.
\end{abstract}

\section{Background}

Pain is defined as 'an unpleasant sensory and emotional experience associated with actual or potential tissue damage, or described in terms of such damage' (Merskey et al., 1979). Pain can be classified as acute or chronic. Acute pain is unpleasant but necessary; it can be a sign that something dangerous, like injury, is occurring in the body.
Nevertheless, there are situations when pain experiences are unnecessary. This happens when pain persists and loses its value as warning signal. This pain is called chronic pain.

Chronic pain is a major health problem. In a recent review, the prevalence of chronic pain was estimated to be $22 \%$ (Andrew et al., 2014). Moreover, chronic pain often leads to psychosocial problems, work disability and health care overutilization (Gupta et al., 2010). Therefore, chronic pain 


\section{What's already known about this topic?}

- The large variation in incidence of chronic after musculoskeletal injury (11-56\%) and prognostic factors is probably due to differences in study design, patient populations and definitions of chronic pain.

\section{What does this study add?}

- In the PROTACT study, a prospective follow-up study including a large population of patients with isolated musculoskeletal injury, a comprehensive set of potential prognostic factors was used to determine incidence and to identify prognostic factors for chronic pain.

- Incidence of chronic pain is $10.1 \%$. Severe pain at discharge and pain catastrophizing are potentially modifiable prognostic factors.

is a substantial economic burden and remains one of the most costly conditions in western society (Sleed et al., 2005).

The link between acute and chronic pain has been subject of investigation in many studies (Holmes et al., 2010; Shipton, 2011). Chronic pain patients often relate their pain onset to acute injury such as surgery or trauma (Crombie et al., 1998; Breivik et al., 2006). However, the transition of acute to chronic pain is a complex and poorly understood developmental process. A range of injury-, psychosocial-, socio-environmental and patient-related factors have been associated with the chronification of pain (Holmes et al., 2010; Shipton, 2011).

Most studies identified prognostic factors for postsurgical chronic pain or chronic whiplash-associated disorder (Kehlet et al., 2006; Walton et al., 2013). Studies that determine prognostic factors for chronic pain post-injury are limited even though chronic pain is a frequent adverse outcome of injury. The incidence of moderate to severe chronic pain after musculoskeletal injury ranges from 11 to $56 \%$, and depends on specific diagnosis (Mkandawire et al., 2002; Urquhart et al., 2006; Moore and LeonardiBee, 2008; Williamson et al., 2009). Multiple factors within the acute phase might be responsible for the transition from acute to chronic pain. Factors known for their predictive validity after musculoskeletal injury are older age, being a woman, preinjury anxiety or depression and severe pain in the acute post-injury period. In contrast, high-educated persons have a reduced risk (Clay et al., 2012).
Most studies investigating prognostic factors for chronic musculoskeletal pain post-injury had a retrospective design, or only two measurements were performed, i.e. at injury and follow-up. Therefore, it is difficult to determine the causality between prognostic factor and the process of chronification. Furthermore, the few current prospective studies included polytrauma patients and might have overestimated the incidence (Castillo et al., 2006; Rivara et al., 2008; Williamson et al., 2009; Holmes et al., 2010).

The PROgnostic factors for the Transition from Acute to Chronic pain in Trauma patients (PROTACT) study is a prospective follow-up study, with the aim to determine prognostic factors responsible for developing chronic pain after isolated musculoskeletal injury. These factors allow the identification of high-risk patients with the aim to provide these patients with appropriate treatment to prevent chronic pain.

\section{Patients and methods}

\subsection{Study design and study population}

This study is part of a l-year prospective follow-up study; the 'PROgnostic factors for the Transition from Acute to Chronic pain in Trauma patients' (PROTACT). Ethics approval for the PROTACT study was obtained from the regional Medical Research Ethics Committee on Research Involving Human Subjects (CCMO no. NL368.38044.11). Adult patients with isolated musculoskeletal extremity injury presenting at the ED of the level 1 trauma centre Medisch Spectrum Twente in Enschede, The Netherlands were invited to participate. The ED has a $24 \mathrm{~h}$ a day, 7 days a week (24/7 ED) service. The ED is accessible for 264,000 individuals in the Twente region and treats approximately 27,000 patients annually.

Eligible patients were consecutively recruited when admitted to the ED from September 2011 until July 2013. Inclusion criteria were: patients (1) who had isolated musculoskeletal extremity injury caused by blunt trauma; (2) who had sufficient communication skills and a basic knowledge of the Dutch language; and (3) aged 18 until 69 years. Exclusion criteria were: patients (1) with life or limb threatening conditions; (2) with documented cognitive disability; (3) suffering from hallucinations, delusions or suicidal ideation; (4) with alcohol or drugs intoxication; and (5) living outside the 'catchment area' 
served by the hospital. During the 22 months inclusion period, 1994 adult patients with musculoskeletal extremity injury attended the ED and met the study criteria. Of these patients, 803 participants provided written informed consent. For the current study, all patients who were followed until 6 months post-injury were included.

\subsection{Data collection}

During the ED admission, patients who met the study criteria were informed by a (triage) nurse about the purpose of the study. Participants were asked to provide informed consent and to complete a questionnaire. These were returned immediately while in the waiting room or send by mail. Eligible patients who were accidently not invited in the ED received an invitation and questionnaire by mail within l week after the ED visit. Six weeks, 3 months and 6 months after the initial ED visit, patients received a follow-up questionnaire by email or by mail, according to their stated preference. Subsequent reminders were sent 1 week later. If the questionnaire was not returned within 3-4 weeks patients were called to ask if they were still willing to fill in the questionnaire. If not, the average pain score in the last week was asked for and the reason for non-participation.

The questionnaires comprised six validated questionnaires that are frequently used in pain research (see below). Furthermore, questions about sociodemographics, self-reported lifestyle and health such as comorbidities, pain management and injury characteristics were included. Moreover, questions about who to blame for the injury and if patient applied for compensation status for bodily insurance were included.

In addition to the data obtained from the questionnaires, data from the ED electronic patient registry were used. Each event is recorded with a timestamp for pre-specified ED events. The registry includes patient demographics (date of birth, sex), referrer, triage urgency level, triage pain score, type of analgesics, medical diagnoses (e.g. injury type and location), type of non-pharmacological pain management and timestamp of providing pain management.

The following six validated questionnaires were used:

\subsubsection{Pain intensity}

Pain intensity at ED admission and ED discharge were measured using Numerical Rating Scales (NRS). Patients were asked to fill in a number from
0 to 10 , where 0 is 'no pain' and 10 'the worst pain imaginable'. The NRS was validated for use in the ED (Bijur et al., 2003; Mohan et al., 2010) and retrospective 1-week recall of pain intensity seems to be reliable and valid (Salovey et al., 1992; Singer et al., 2001).

\subsubsection{Health-related quality of life}

Health-related quality of life (HRQOL) was measured by using the validated Dutch language version of the 36-Item Short-Form Health Survey (SF-36, Corporation, Santa Monica, CA, USA) (Aaronson et al., 1998). The SF-36 is a general quality of life questionnaire with a 4-week recall period and assesses eight domains: physical functioning, social functioning, role limitations due to physical problems, role limitations due to emotional problems, pain, mental health, vitality and general health perception (Ware and Sherbourne, 1992). For each domain, item scores were coded, summed and transformed into a scale ranging from 0 to 100, where 100 was the highest best possible rating. Algorithms were used to produce the Physical Component Summary (PCS) scores for physical health status and Mental Component Summary (MCS) scores for mental health status (Ware et al., 1994). In the present study, the first quartiles of the obtained PCS (51.9) and MCS (49.9) scores were defined as the cut-off points for poor mental or physical health (Alishiri et al., 2008).

\subsubsection{Anxiety and depression}

Anxiety and depression were measured using the Hospital Anxiety and Depression Scale (HADS). The Dutch version was validated and was found to have good psychometric properties (Spinhoven et al., 1997). The HADS is a screening tool used in a wide variety of clinical groups, such as emergency care patients (Weijenborg et al., 2010) and chronic musculoskeletal patients (Pallant and Bailey, 2005). Patients were asked to recall a 7-day period about 14 items on a 4-point Likert scale; anxiety and depression sum scores were calculated (range 0-21), with a high score indicating a high level of anxiety or depression. In the present study, a sum score of $>7$ was used to indicate the presence of anxiety and depression.

\subsubsection{Pain catastrophizing}

Pain catastrophizing was measured by using a Dutch language version of the Pain Catastrophizing Scale 
(PCS) consisting of 13 statements of pain experience; for example: 'If I am in pain, I am afraid the pain will get worse.' Patients were asked to indicate whether they agree with these statements by using a 5-point Likert scale. A PCS sum score was calculated from all items (range 0-52), with a high score indicating a high level of pain catastrophizing. In this study, a score of $>24$ was used to indicate the presence of pain catastrophizing, because this cut-off point was found to be best associated with high follow-up pain ratings (Scott et al., 2013). Several studies support the validity and reliability of PCS (Van Damme et al., 2002).

\subsubsection{Kinesiophobia}

Kinesiophobia was measured by the Tampa Scale of Kinesiophobia (TSK). The TSK consists of 17 statements that reflect the notion that pain is a precursor for (re)injury because of physical activity or certain movements (Miller et al., 1991). Patients were asked whether they agree with these statements by using a 4-point Likert scale. A TSK sum score was calculated by using all items (range 17-68). A score of 37 or higher was used to indicate the presence of kinesiophobia (Vlaeyen et al., 1995). The Dutch language version TSK has been shown to be internally reliable and correlates with measures of other disability (Vlaeyen et al., 1995).

\subsubsection{Pain experience during follow-up}

Pain experience at 6-week, 3- and 6-month followup was measured using a few questions of the Brief Pain Inventory (BPI) - long version (Cleeland, 1989). The BPI is a self-reporting instrument to assess the multidimensional nature of pain, including pain intensity and pain interference on life activities. Pain intensity in patient's injured body part was measured four times: 'worst pain last week', 'least pain last week', 'average pain last week' and 'current pain', using the NRS related to their injury, where 0 is 'no pain' and 10 is 'the worst pain imaginable'. Patients also rated how much their pain interfered with daily activities and sleep during the past week, where 0 is 'does not interfere' and 10 is 'interferes completely'. BPI has a good reliability and validity for assessing pain intensity in patients with chronic non-malignant pain (Tan et al., 2004).

\subsection{Primary outcome measure at follow-up}

The primary outcome at 6 months post-injury was chronic pain. This was based on the BPI 'rate your average pain last week'. The cut-off score for chronic pain was set at NRS $\geq 4$ (Lempa et al., 2000; Althaus et al., 2012). In addition, the pain intensity pattern over time in the post-injury period of each patient with a NRS $\geq 4$ was observed to determine if the pain was persistent after injury. If pain was not present during the whole period (NRS $\geq 2$ at 6 weeks, 3 months), patients were indicated as not having chronic pain. Secondary outcome at 6 months was pain interference with daily activities.

\subsection{Potential prognostic factors}

The following variables were analysed for their prognostic value (Holmes et al., 2010; Shipton, 2011):

\subsubsection{Demographics}

Age, sex, educational level, marital status, income/ employment status and lifestyle factors (alcohol consumption and smoking).

\subsubsection{Pain factors}

Pain intensity at discharge measured with NRS; chronic pain in the past or at the time of filling in the questionnaire; pain interference with activities in the month before injury measured (none/little vs. moderately/quite a bit/extremely) with SF-36; and the use of analgesics in the ED.

\subsubsection{Psychosocial factors}

Pre-injury anxiety and depression measured with HADS; catastrophizing measured with PCS; kinesiophobia measured with TSK; and mental health status measured with SF-36.

\subsubsection{Injury and treatment factors}

Type of injury, site of injury, previous injury on injured body part, urgency level and surgery.

\subsubsection{Clinical factors}

Physical health status measured with SF-36, self-reported comorbidities and body mass index.

\subsubsection{Others}

Compensation status and blame of the injury.

\subsection{Data analysis}

For descriptive purposes, categorical data were characterized in terms of frequency $(\%)$, whereas 
continuous data were characterized as median with interquartile range (IQR, 25th-75th percentile) or as mean \pm standard deviation (SD). Generalized Linear Model (GLM) for repeated measures was used to investigate differences in pain scores over time between patients who developed chronic pain and those who did not. Pearson correlation coefficient between primary outcome pain intensity and pain interference with daily activities at 6 months was measured.

Associations between categorical variables and chronic pain 6 months post-injury were investigated using chi-squared tests. Odds ratios (ORs) and corresponding 95\% confidence intervals (CI) were calculated and interpreted as the relative risk of the presence of a potential prognostic factor for chronic pain compared to the absence of that prognostic factor. Because pre-selection of prognostic factors based on $p$-values estimated from univariate analyses may result in unstable prediction models (Harrell et al., 1996), all candidate variables were considered in the multivariate analysis. Backward stepwise selection of all candidate variables was applied using the likelihood ratio test with a $p$-value of 0.157 according to Akaike's information criterion. This Akaike variant is a measure of model fit that includes a penalty against large models and hence attempts to reduce overfitting (Sauerbrei, 1999).

If multicollinearity between two variables was suspected, change of estimates, confidence intervals and $p$-values were evaluated when both variables were included in the model as compared to the inclusion of one variable. If the two variables were more or less equally associated with the chronic pain we selected the variable most easily obtainable in clinical practice. The model's ability to discriminate non-chronic from chronic pain patients was assessed by concordance $(c)$-statistic. The $c$-statistic equals the area under the receiver operating characteristic (ROC) curve in logistic regression. The c-statistic can range from 0.5 (no discrimination) to 1.0 (perfect) discrimination. The $c$-statistic for a prognostic model is typically between about 0.6 and 0.85 (Royston et al., 2009).

A bootstrapping procedure was used to assess the internal validity of the multivariate model. Two hundred and fifty bootstrap samples were drawn from the data set. In each bootstrap sample, the modelling was repeated. This procedure produced a corrected model's $c$-statistic and a shrinkage factor. The regression coefficients $(\beta)$ of the prognostic factors in the model were then multiplied by this shrinkage factor to prevent overfitting of the regression coefficients and optimism of the model when applied to new patients. The adjusted odds ratios (ORadj) and corresponding 95\% CIs were calculated. In the final model, the $R^{2}$ Nagelkerke was used as a measure of the power of combined variables in predicting chronic pain. For the variables that turned out as independent prognostic factors, the observed and predicted proportions of patients reporting chronic pain were calculated. All data analyses were performed with SPSS version 21.0 (IBM Corporation, Armonk, NY, USA) and R software version 3.0.3 ( $\mathrm{R}$ foundation, Vienna, Austria).

\section{Results}

\subsection{Patients and pain characteristics}

Between September 2011 and July 2013, 803 adult patients with musculoskeletal extremity injury provided written informed consent. Data on a total of 435 patients, who filled in baseline and follow-up questionnaires at 6 weeks, 3 and 6 months, were used for analysis. Distributions of age and sex among these 435 patients were slightly different from the 368 patients who did not fill in all four questionnaires; more women and an older age. Median age of the 435 patients was 50.0 years (IQR 36.0-60.0) and $60.5 \%$ were women (Table 1 ). The majority of 435 patients suffered a fracture $(75.4 \%)$. Most common body parts where fractures occurred were wrist $(n=69)$; ankle $(n=56)$, elbow $(n=31)$, metatarsalia $(n=30)$ and hip $(n=24)$.

Of all patients, $43.9 \%$ had some degree of pain 6 months post-injury: $33.8 \%$ had minimal pain (NRS 1-3); $8.3 \%$ had moderate pain (NRS 4-6); and $1.8 \%$ reported severe pain (NRS $\geq 7$ ) (Fig. 1).

According to the cut-off score of chronic pain (NRS $\geq 4), 44$ of 435 patients $(10.1 \%)$ suffered chronic pain at 6 months post-injury. Most patients $(77.5 \%)$ who reported some degree of pain also had pain interference during daily activities (Fig. 1). The correlation between pain intensity and pain interference at 6 months post-injury was high $(r=0.84$ $p<0.01$ ).

Fig. 2 shows the mean pain intensity over time from ED admission until 6 months post-injury separately for patients who developed chronic pain 6 months post-injury and for non-chronic pain patients. Chronic pain patients had a higher pain intensity score on ED admission $(p<0.01)$. There was no difference in pain reduction over time from ED admission till discharge (GLM for repeated measures, $p=0.90$ ) and from discharge to 6-week 
Table 1 Characteristics of 435 patients with musculoskeletal extremity injury.

\begin{tabular}{|c|c|}
\hline Variable & $N(\%)$ \\
\hline \multicolumn{2}{|l|}{ Sociodemographics } \\
\hline \multicolumn{2}{|l|}{ Sex } \\
\hline Women & $263(60.5 \%)$ \\
\hline Age (in years), median (IQR) & $50.0(36.0-60.0)$ \\
\hline \multicolumn{2}{|l|}{ Educational level } \\
\hline High & $144(33.1 \%)$ \\
\hline Middle & $227(51.8 \%)$ \\
\hline Low & $62(14.3 \%)$ \\
\hline \multicolumn{2}{|l|}{ Marital status } \\
\hline Married/domestic partnership & $297(68.8 \%)$ \\
\hline Divorced & $13(3.0 \%)$ \\
\hline Widowed & $20(4.6 \%)$ \\
\hline Single & $103(23.8 \%)$ \\
\hline \multicolumn{2}{|l|}{ Work income } \\
\hline Modal & $64(14.7 \%)$ \\
\hline Lower than modal & $100(23.0 \%)$ \\
\hline Higher than modal & 70 (16.1\%) \\
\hline No (income out) of work & $157(36.1 \%)$ \\
\hline Prefers not to give this information & $44(10.1 \%)$ \\
\hline \multicolumn{2}{|l|}{ Alcohol consumption before injury } \\
\hline Weekly or less & $190(44.0 \%)$ \\
\hline More than once a week & $242(56.0 \%)$ \\
\hline \multicolumn{2}{|l|}{ Smoking } \\
\hline Yes & $62(14.4 \%)$ \\
\hline \multicolumn{2}{|l|}{ Pain factors } \\
\hline Pain intensity at admission ED, mean (SD) & $6.5(2.4)$ \\
\hline Used analgesics in the ED & $160(36.8 \%)$ \\
\hline Pain intensity at discharge ED, mean (SD) & $5.6(2.5)$ \\
\hline Pre-existing chronic pain & $88(20.2 \%)$ \\
\hline \multicolumn{2}{|l|}{$\begin{array}{l}\text { Pain interferes with daily activities } \\
\text { before injury }\end{array}$} \\
\hline None/little & $398(91.5 \%)$ \\
\hline Moderately/quite a bit/extremely & $37(8.5 \%)$ \\
\hline \multicolumn{2}{|l|}{ Psychological factors } \\
\hline Anxiety before injury, mean (SD) & $3.5(2.9)$ \\
\hline Depression before injury, mean (SD) & $1.8(2.6)$ \\
\hline Kinesiophobia, mean (SD) & $35.9(6.8)$ \\
\hline Pain catastrophizing, mean (SD) & $8.4(7.1)$ \\
\hline $\begin{array}{l}\text { Mental health before injury, } \\
\text { mean (SD) }\end{array}$ & $52.3(8.4)$ \\
\hline \multicolumn{2}{|l|}{ Injury and treatment factors } \\
\hline \multicolumn{2}{|l|}{ Type of injury } \\
\hline Fracture & $328(75.4 \%)$ \\
\hline Dislocation & $25(5.7 \%)$ \\
\hline Sprains and strains & $47(10.8 \%)$ \\
\hline Contusion & $24(5.5 \%)$ \\
\hline Muscle rupture & $10(2.3 \%)$ \\
\hline \multicolumn{2}{|l|}{ Site of injury } \\
\hline Lower extremities & $215(49.4 \%)$ \\
\hline \multicolumn{2}{|l|}{ Urgency level } \\
\hline Standard & $301(69.4 \%)$ \\
\hline Urgent & $114(26.3 \%)$ \\
\hline Very urgent & $19(4.4 \%)$ \\
\hline \multicolumn{2}{|l|}{ Earlier injury on injured body part } \\
\hline Yes & $98(22.5 \%)$ \\
\hline
\end{tabular}

Table 1 (Continued)

\begin{tabular}{ll}
\hline Variable & $N(\%)$ \\
\hline $\begin{array}{l}\text { Surgery } \\
\text { Yes } \\
\text { Complications post-injury } \\
\quad \text { Yes }\end{array}$ & $104(23.9 \%)$ \\
Clinical factors & $22(5.1 \%)$ \\
$\quad$ Physical health before injury, & \\
mean sum score & $53.5(8.4)$ \\
Comorbidity (self-reported) Yes & \\
BMI, mean (SD) & $131(30.1 \%)$ \\
Other & $25.2(4.2)$ \\
Compensation status & \\
$\quad$ Yes & \\
Trauma caused & $34(7.9 \%)$ \\
$\quad$ Self-injured & \\
$\quad$ Third-party caused & $394(90.6 \%)$ \\
Follow-up & $41(9.4 \%)$ \\
Follow-up in months, median IQR & \\
Pain (NRS $\geq 1$ ) at 6-month follow-up & $6.3(6.1-6.8)$ \\
Chronic pain (NRS $\geq 4)$ at 6-month & $191(43.9 \%)$ \\
follow-up & $44(10.1 \%)$ \\
Pain disability (NRS $\geq 4)$ with daily & \\
activity at 6-month follow-up & $48(11.0 \%)$ \\
\end{tabular}

follow-up (GLM for repeated measures, $p=0.53$ ) between patients who developed chronic pain and those who did not. After 6 weeks, there was some increase in pain among chronic pain patients, in contrast to pain reduction in patients who did not develop chronic pain (GLM for repeated measures $p=0.16$ ). After 3 months, the differences in pain experience over time between the two groups further increased significantly over time (GLM for repeated measures $p<0.01$ ).

\subsection{Prognostic factors of chronic pain}

To examine possible variables that account for developing chronic pain, the association between potential prognostic factors and chronic pain at 6 months was investigated (Table 2). Most potential predictors were to some extent associated with chronic pain 6 months post-injury. All pain factors, an increased age, pain catastrophizing, having comorbidities, physical health before injury and urgency level are significantly associated with chronic pain.

Only six prognostic factors (age $\geq 40$ years, poor physical health status, pre-existing chronic pain before injury, pain catastrophizing, (very) urgent urgency level and severe pain at discharge) independently contributed to the prediction of chronic pain (Table 3). Other prognostic factors, which seemed relevant such as sex, kinesiophobia and comorbidi- 


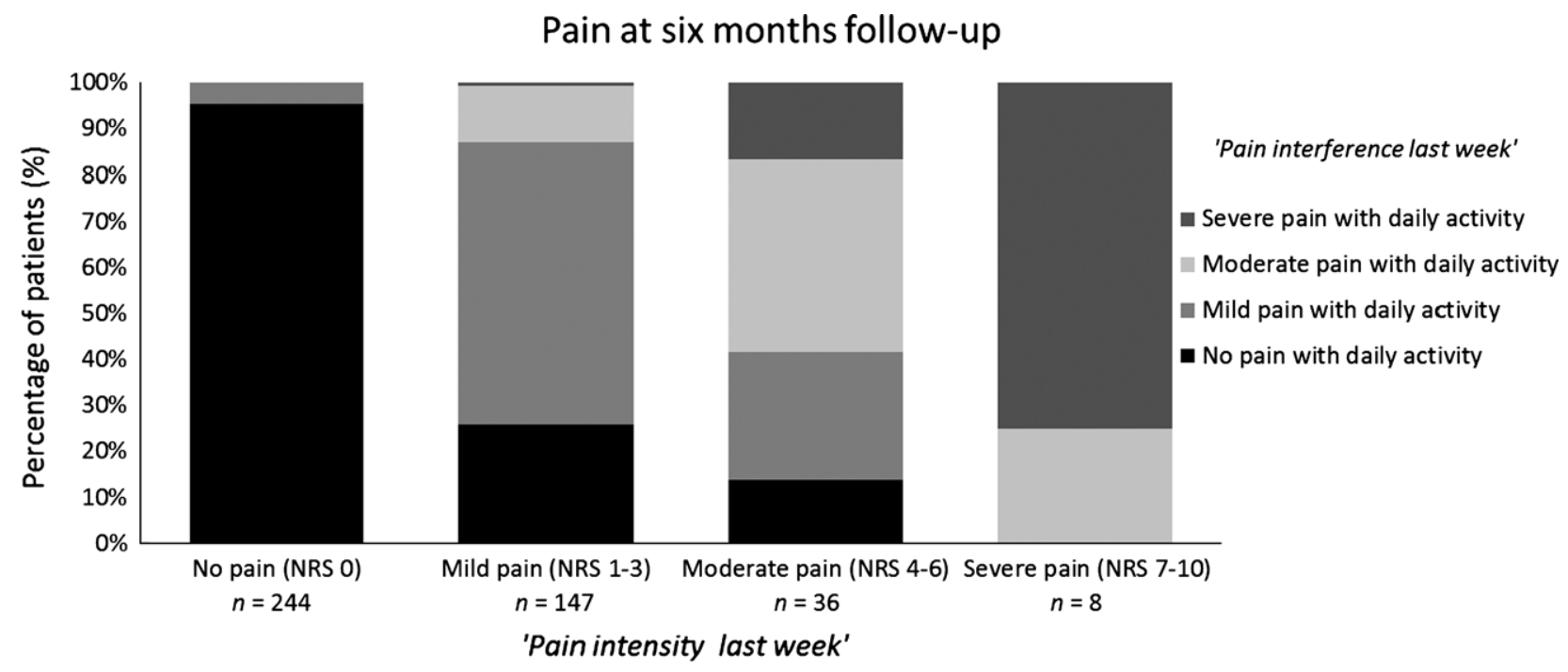

Figure 1 Percentage of patients with pain intensity and pain interference with daily activities at 6 months post-injury.

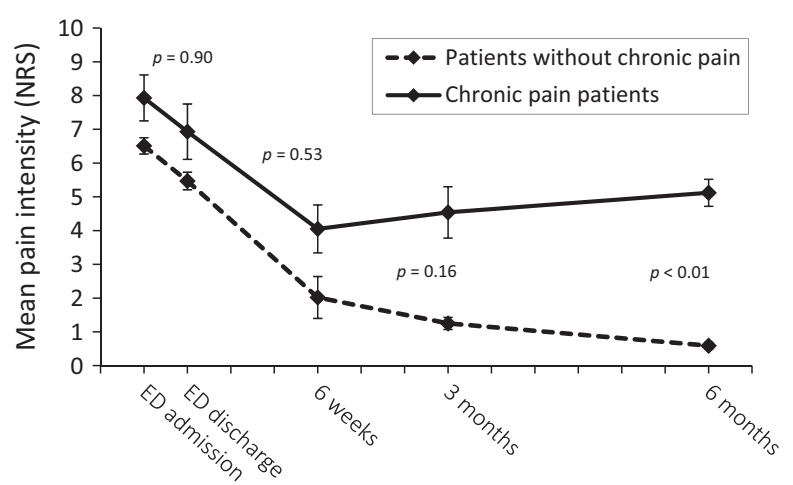

Figure 2 Mean $( \pm 95 \% \mathrm{Cl}$ ) pain intensity of chronic pain patients and patients without chronic pain over time. Differences were assessed with the General Linear Model method for analysing repeated measures.

ties in univariate analyses, were not independent prognostic factors. Apparently, their predictive information was already provided by the remaining prognostic factors. The final model including the six prognostic factors showed a good calibration (Hosmer-Lemeshow test $p=0.88$ ) and discriminative ability (c-statistic $0.81 ; 95 \%$ CI $0.74-0.88$ ). The final model is able to predict $19 \%$ of the chronic pain at 6 months post-injury. Internal validity was strong; the bootstrapping procedure yielded an optimismcorrected $c$-statistic of 0.80 and a shrinkage factor of 0.88 . The best trade-off between sensitivity (no false negatives) and specificity (no false positives) was, respectively, 0.71 and 0.77 (Fig. 3). The presence of pre-existing chronic pain before injury was the strongest prognostic factor for developing chronic pain: patients who already had chronic pain were four times (ORadj 3.99; 95\% CI 2.07-7.69) more likely to develop chronic pain in the injured body part. Pain catastrophizing (ORadj 3.16; 95\% CI 0.9610.43 ) and severe pain at discharge (ORadj 1.89: 95\% CI 0.98-3.66) are potential modifiable factors.

With the risk score presented underneath Table 3, the risk of developing chronic pain 6 months postinjury can be calculated for each individual patient. The number of patients reporting chronic pain increases linearly with every additional prognostic factor. Patients who present at the ED with no or only one prognostic factor have a risk of $0-3 \%$ to develop chronic pain, patients with two prognostic factors have a risk of $6 \%$, with three a risk of $17 \%$, with four a risk $32 \%$ and patients with five prognostic factors have a risk of $50 \%$. None of the patients had all six prognostic factors.

\section{Discussion}

In this prospective follow-up study, $43.9 \%$ of all 435 patients had some degree of pain and $10.1 \%$ had chronic pain 6 months after isolated musculoskeletal extremity injury. Patients aged over 40 years, in poor physical health and with pre-existing chronic pain before injury, pain catastrophizing, (very) urgent urgency level and severe pain at discharge were more prone to develop chronic pain. Two prognostic factors, severe pain at discharge and pain catastrophizing, are potentially modifiable in the ED or within the first few days after discharge. Although the others factors are not modifiable, these can still be used to identify high-risk patients, which may 
Table 2 Factors associated with chronic pain (NRS $\geq 4$ ) 6 months post-injury $(N=435)$.

\begin{tabular}{|c|c|c|c|}
\hline Variable & $\begin{array}{l}\text { Chronic } \\
\text { pain }(n)\end{array}$ & OR $(95 \% \mathrm{Cl})$ & $p$ \\
\hline \multicolumn{4}{|l|}{ Sociodemographics } \\
\hline \multicolumn{4}{|l|}{ Sex } \\
\hline Men (ref.) & $12 / 172$ & 1 & \multirow[t]{2}{*}{0.08} \\
\hline Women & $32 / 263$ & $1.85(0.93-3.70)$ & \\
\hline \multicolumn{4}{|l|}{ Age (in years) } \\
\hline 18-39 (ref.) & $6 / 128$ & 1 & \multirow[t]{4}{*}{$<0.01$} \\
\hline $40-49$ & $4 / 83$ & $1.03(0.28-1.07)$ & \\
\hline $50-59$ & $16 / 111$ & $3.43(1.29-9.09)$ & \\
\hline $60-69$ & $54 / 113$ & $3.85(1.47-10.08)$ & \\
\hline \multicolumn{4}{|l|}{ Educational level $^{a}$} \\
\hline High (ref.) & $10 / 144$ & 1 & \multirow[t]{3}{*}{0.13} \\
\hline Middle & $24 / 227$ & $1.58(0.73-3.42)$ & \\
\hline Low & $10 / 62$ & $2.57(1.01-6.55)$ & \\
\hline \multicolumn{4}{|l|}{ Marital status ${ }^{a}$} \\
\hline $\begin{array}{l}\text { Married/domestic } \\
\text { partnership (ref.) }\end{array}$ & $34 / 297$ & 1 & \multirow[t]{4}{*}{0.11} \\
\hline Divorced & $1 / 13$ & $0.65(0.08-5.11)$ & \\
\hline Widowed & $4 / 20$ & $1.93(0.61-6.12)$ & \\
\hline Single & $5 / 103$ & $0.40(0.15-1.04)$ & \\
\hline \multicolumn{4}{|l|}{ Work income } \\
\hline Modal (ref.) & $6 / 64$ & 1 & \multirow[t]{5}{*}{0.08} \\
\hline Lower than modal & $8 / 100$ & $0.84(0.28-2.55)$ & \\
\hline Higher than modal & $3 / 70$ & $0.43(0.10-1.81)$ & \\
\hline No (income out) of work & $24 / 157$ & $1.74(0.68-4.49)$ & \\
\hline $\begin{array}{l}\text { Prefers not to give } \\
\text { this information }\end{array}$ & $3 / 44$ & $0.71(0.17-2.99)$ & \\
\hline \multicolumn{4}{|l|}{$\begin{array}{l}\text { Alcohol consumption } \\
\text { before injurya }\end{array}$} \\
\hline Weekly or less (ref.) & $23 / 190$ & 1 & \multirow[t]{2}{*}{0.19} \\
\hline More than once a week & $20 / 242$ & $0.65(0.35-1.23)$ & \\
\hline \multicolumn{4}{|l|}{ Smoking ${ }^{a}$} \\
\hline No (ref.) & $34 / 370$ & 1 & \multirow[t]{2}{*}{0.20} \\
\hline Yes & $9 / 62$ & $1.68(0.76-3.70)$ & \\
\hline \multicolumn{4}{|l|}{ Pain factors } \\
\hline \multicolumn{4}{|l|}{ Used analgesics in the ED } \\
\hline No (ref.) & $21 / 275$ & 1 & \multirow[t]{2}{*}{0.03} \\
\hline Yes & $23 / 160$ & $2.03(1.09-3.80)$ & \\
\hline \multicolumn{4}{|l|}{ Pain level at discharge ED } \\
\hline No severe pain (ref.) & $13 / 243$ & 1 & \multirow[t]{2}{*}{$<0.01$} \\
\hline Severe pain [NRS $\geq 7]$ & $31 / 192$ & $3.41(1.73-6.71)$ & \\
\hline \multicolumn{4}{|l|}{ Pre-existing chronic pain ${ }^{a}$} \\
\hline Absent or in the past (ref.) & $20 / 345$ & 1 & \multirow[t]{2}{*}{$<0.01$} \\
\hline Present & $24 / 88$ & $6.09(3.18-11.69)$ & \\
\hline $\begin{array}{l}\text { Pain interferes with daily } \\
\text { activities before injury }\end{array}$ & & & \\
\hline None/little (ref.) & $35 / 398$ & 1 & $<0.01$ \\
\hline $\begin{array}{l}\text { Moderately/quite a } \\
\text { bit/extremely }\end{array}$ & $9 / 37$ & $3.33(1.46-7.62)$ & \\
\hline Psychological factors & & & \\
\hline Anxiety before injury ${ }^{a}$ & & & \\
\hline No (ref.) & $37 / 392$ & 1 & 0.12 \\
\hline Present & $7 / 41$ & $1.98(0.82-4.77)$ & \\
\hline Depression before injury ${ }^{a}$ & & & \\
\hline No (ref.) & $40 / 413$ & 1 & 0.14 \\
\hline Present & $4 / 20$ & $2.33(0.74-7.31)$ & \\
\hline
\end{tabular}

Table 2 (Continued)

\begin{tabular}{|c|c|c|c|}
\hline Variable & $\begin{array}{l}\text { Chronic } \\
\text { pain (n) }\end{array}$ & $\mathrm{OR}(95 \% \mathrm{Cl})$ & $p$ \\
\hline \multicolumn{4}{|l|}{ Kinesiophobia $^{c}$} \\
\hline No (ref.) & $18 / 227$ & 1 & \multirow[t]{2}{*}{0.09} \\
\hline Present & $24 / 184$ & $1.74(0.91-3.32)$ & \\
\hline \multicolumn{4}{|l|}{ Pain catastrophizing ${ }^{b}$} \\
\hline No (ref.) & $38 / 404$ & 1 & \multirow[t]{2}{*}{0.02} \\
\hline Present & $4 / 14$ & $3.85(1.15-12.88)$ & \\
\hline \multicolumn{4}{|l|}{ Mental health before injury ${ }^{a}$} \\
\hline Good (ref.) & $30 / 325$ & 1 & \multirow[t]{2}{*}{0.28} \\
\hline Poor & $14 / 109$ & $1.45(0.74-2.85)$ & \\
\hline \multicolumn{4}{|l|}{ Injury and treatment factors } \\
\hline Type of injury & & & \\
\hline Fracture (ref.) & $37 / 328$ & 1 & \multirow{6}{*}{0.16} \\
\hline Non-fracture & $7 / 107$ & $0.55(0.24-1.27)$ & \\
\hline Dislocation & $3 / 25$ & $1.07(0.31-3.76)$ & \\
\hline Sprains and strains & $3 / 47$ & $0.54(0.16-1.81)$ & \\
\hline Contusion & $0 / 24$ & - & \\
\hline Muscle rupture & $1 / 10$ & $0.87(0.11-7.09)$ & \\
\hline \multicolumn{4}{|l|}{ Site of injury } \\
\hline Lower extremities (ref.) & $24 / 215$ & 1 & \multirow[t]{2}{*}{0.47} \\
\hline Upper extremities & $20 / 220$ & $0.80(0.43-1.49)$ & \\
\hline \multicolumn{4}{|l|}{ Urgency level } \\
\hline Standard (ref.) & $23 / 301$ & 1 & \multirow[t]{3}{*}{0.01} \\
\hline Urgent & $16 / 114$ & $1.97(1.00-3.89)$ & \\
\hline Very urgent & $5 / 19$ & $4.03(1.34-12.07)$ & \\
\hline \multicolumn{4}{|c|}{ Earlier injury on injured body part } \\
\hline No (ref.) & $31 / 337$ & 1 & \multirow[t]{2}{*}{0.24} \\
\hline Yes & $13 / 98$ & $1.51(0.76-3.02)$ & \\
\hline \multicolumn{4}{|l|}{ Surgery } \\
\hline No (ref.) & $30 / 331$ & 1 & \multirow[t]{2}{*}{0.19} \\
\hline Yes & $14 / 104$ & $1.56(0.79-3.07)$ & \\
\hline \multicolumn{4}{|l|}{ Complications post-injury } \\
\hline No (ref.) & $40 / 413$ & 1 & \multirow[t]{2}{*}{0.20} \\
\hline Yes & $4 / 22$ & $2.07(0.67-6.42)$ & \\
\hline \multicolumn{4}{|l|}{ Clinical factors } \\
\hline \multicolumn{4}{|l|}{ Physical health before injury ${ }^{a}$} \\
\hline Good (ref.) & $23 / 326$ & 1 & \multirow[t]{2}{*}{$<0.01$} \\
\hline Poor & $21 / 108$ & $3.18(1.68-6.02)$ & \\
\hline Comorbidity & & & \\
\hline No (ref.) & $21 / 304$ & 1 & $<0.01$ \\
\hline Yes & $23 / 131$ & $2.87(1.53-5.40)$ & \\
\hline BMI (international classifica & & & \\
\hline Normal weight (ref.) & $19 / 233$ & 1 & 0.22 \\
\hline Underweight & $0 / 6$ & - & \\
\hline Overweight & $17 / 143$ & $1.52(0.76-3.03)$ & \\
\hline Obesity & $8 / 48$ & $2.25(0.92-5.50)$ & \\
\hline Other & & & \\
\hline Compensation status $^{a}$ & & & \\
\hline No (ref.) & $38 / 397$ & 1 & 0.14 \\
\hline Yes & $6 / 34$ & $2.02(0.79-5.20)$ & \\
\hline Trauma caused & & & \\
\hline Self-injured (ref.) & $42 / 394$ & 1 & 0.24 \\
\hline Third-party caused & $2 / 41$ & $0.43(0.10-1.84)$ & \\
\hline
\end{tabular}

${ }^{a}<5$ missing values.

$\mathrm{b}_{17}$ missing values.

${ }^{c} 27$ missing values.

Ref $=$ reference group. 
Table 3 Independent factors associated with pain (NRS $\geq 4$ ) 6 months post-injury ( $n=397)$. $^{\text {a }}$

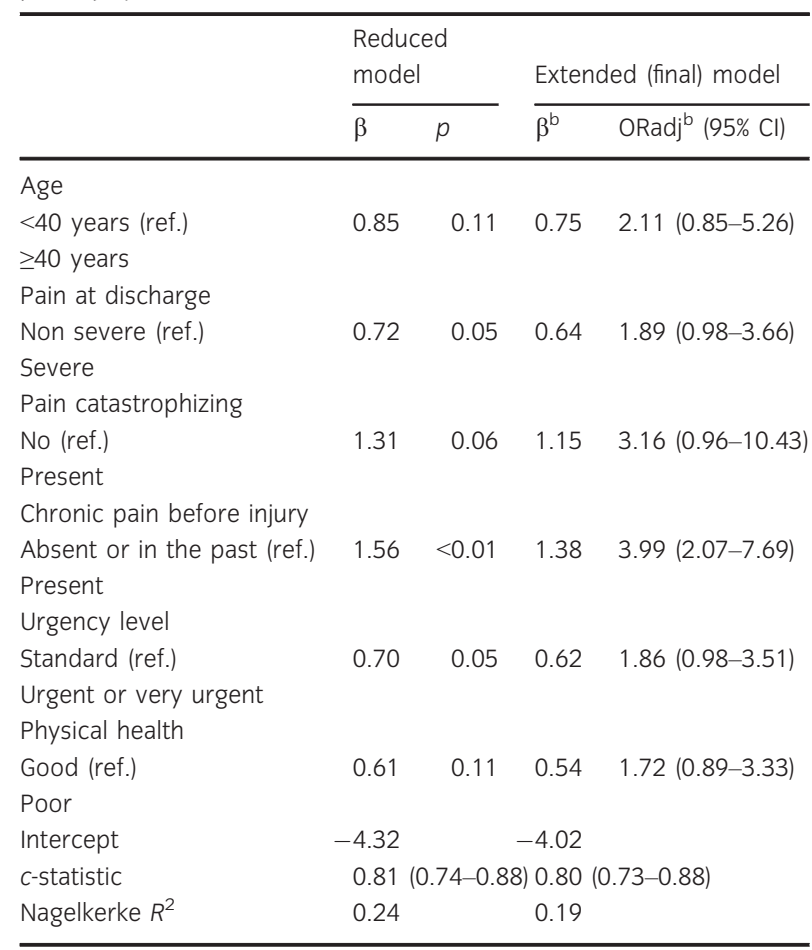

\footnotetext{
A Thirty-eight missing values in multivariate analysis.

${ }^{b}$ Regression coefficient and corresponding odds ratio after bootstrapping (i.e. adjusted for overfitting). The shrinkage factor was 0.8823 .

Ref. = reference group.

Probability of developing chronic pain $=1 /\left(1+\exp \left(-\left(-4.02+0.75^{*}\right.\right.\right.$ (age_ $\geq 40$ years) $+0.64 *$ (pain at discharge_severe) $+1.15 *$ (pain catastrophizing_present) $+1.38^{*}$ (pre-existing chronic pain before injury_present) $+0.62 *$ (urgency level_urgent or very urgent) $+0.54 *$ (physical health_poor)).
}

have implications for patient information and the perspective of medical treatment and health care provision.

The question arises as to whether the potentially modifiable prognostic factors can contribute to a better clinical outcome and how. The PROTACT study shows that patients with severe pain at ED discharge have an almost two times higher risk of developing chronic pain as patients who were not. Severe acute pain has already shown to be one of the most consistent prognostic factors in developing chronic pain after surgery (VanDenKerkhof et al., 2013). Moreover, there is strong evidence that high pain intensity at discharge or early post-injury is associated with chronic pain (Holmes et al., 2010). One of the theories postulated for this progression from severe acute to chronic pain is central sensitization, whereby the nociceptive neurons increase their

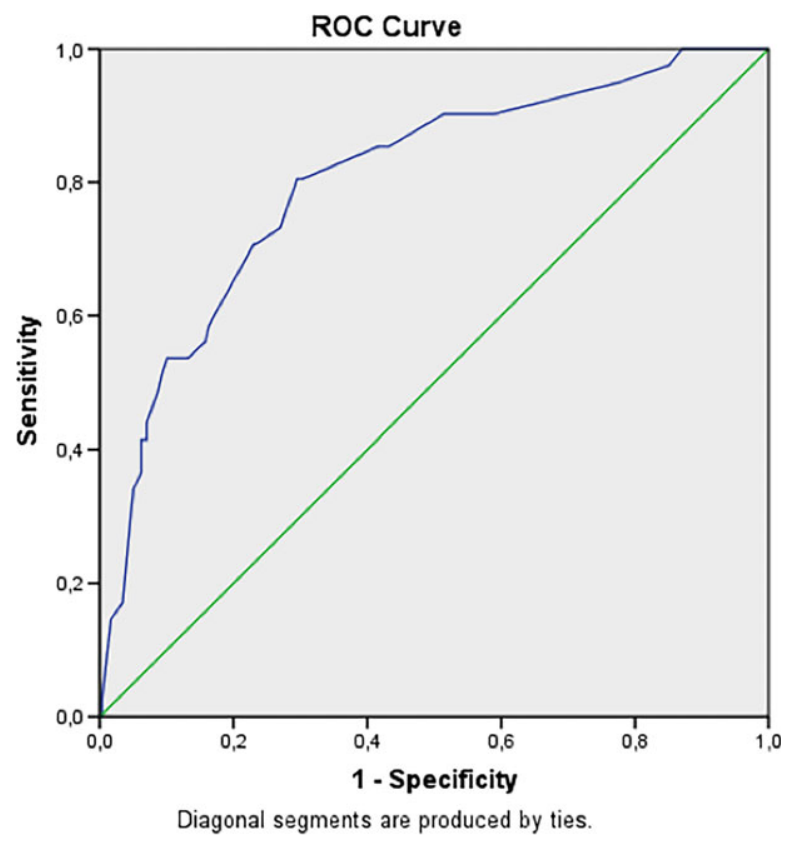

Figure 3 c-statistic (ROC area $=0.80$ ) of the final prediction model. Best trade-off for chronic pain prediction was with sensitivity 0.71 and specificity 0.77

response to non-painful stimuli and develop spontaneous activity (Kyranou and Puntillo, 2012).

One of the primary goals in the ED is the prompt, effective alleviation of pain. Acute pain relief is important for humanitarian reasons. Perhaps of equal, or arguably more importance, adequate and effective pain treatment may reduce or even terminate the progression from acute to chronic pain. The inadequate and ineffective pain treatment within the ED is a well-documented problem worldwide (Motov and Khan, 2009). The introduction of a pain protocol may improve pain management in the ED and decrease the percentage $(44 \%)$ of patients discharged with severe pain. Studies have reported that such protocols improve the amount of and shortens the time to analgesic provision (Seguin, 2004; Kelly et al., 2005).

Another potentially modifiable prognostic factor is pain catastrophizing, which is characterized by the tendency to magnify the threat value of a pain stimulus - to feel helpless in the context of pain, and by a relative inability to inhibit pain-related thoughts in anticipation of a painful experience (Quartana et al., 2009). Pain catastrophizing has been associated with a number of important pain-related outcomes, including chronic pain (Sullivan et al., 2001; Keefe et al., 2004). The PROTACT study confirms that patients who catastrophize their pain are three times 
more prone to develop chronic pain than patients who do not. Given pain catastrophizing is associated with different pain-related outcomes, as well as with neural, physiological, cognitive, affective and interpersonal factors associated with pain and suffering, it follows that a decrease of pain catastrophizing behaviour might reduce the development of chronic pain. Cognitive-behavioural techniques involving reducing catastrophizing and enhancing adaptive pain-coping skills are nowadays a core component of multidisciplinary pain treatment especially in chronic pain patients (Quartana et al., 2009). These techniques might be useful to prevent progression from acute to chronic pain.

Other prognostic factors found in the PROTACT study are older age, poor physical health, chronic pain before injury and a higher urgency level. These prognostic factors are not entirely consistent with the results of a recent systematic review on prognostic factors for chronic pain after orthopaedic trauma where patients who were older, women, or those who reported anxiety or depression before injury or severe pain in the acute post-injury period, were identified as more likely to develop chronic pain. High-educated persons had a reduced risk (Clay et al., 2012). Poor physical health, which the PROTACT study identified as a prognostic factor, was earlier identified as a prognostic factor (Atherton et al., 2006; Rivara et al., 2008). The same is true for having pre-existing chronic pain before injury (Williamson et al., 2009; Holmes et al., 2010). In the PROTACT study, patients with pre-existing chronic pain were four times more likely to develop chronic pain at their injured body part. Moreover, in $87.5 \%$ of these patients, the body part affected by pre-existing chronic pain was different from the affected body part at 6 months post-injury.

A higher urgency level, indicative of a more severe injury, was a prognostic factor which is in agreement with a study of chronic pain after neck injuries (Atherton et al., 2006).

Although many studies conclude that women are at higher risk of developing chronic pain (Sterner et al., 2003; Katz et al., 2005; Clay et al., 2012), in the PROTACT study this effect disappeared after using other factors in the model. Although many psychological factors such as anxiety, depression (Kalkman et al., 2003; Rivara et al., 2008; Clay et al., 2012) and kinesiophobia (Nederhand et al., 2004; Grotle et al., 2007) have been associated with developing chronic pain, the PROTACT study only found pain catastrophizing to be associated with chronic pain in a model with other factors. Explanation for this might be that pain catastrophizing shares significant variance with these other negative affect-related constructs of pain (Mounce et al., 2010).

Chronic pain after injury has received considerable attention the last decade yet there is no agreement regarding the definition or measurement. This explains some of the variation in incidence of chronic pain between studies. In our population almost $44 \%$ of the patients had some degree of pain 6 months post-injury, but only 1 of 10 patients developed chronic pain defined as having a pain score of NRS $\geq 4$. This incidence of chronic musculoskeletal pain post-injury is lower than found in other studies, which ranges from 11 to $56 \%$, and depends on specific diagnostic injury and time of assessing (Mkandawire et al., 2002; Urquhart et al., 2006; Moore and Leonardi-Bee, 2008; Williamson et al., 2009). Furthermore, differences in incidence between studies might be explained by in- or excluding polytrauma patients. An Australian study shows differences in pain outcomes between patients with isolated orthopaedic injury, patients with multiple orthopaedic injuries (without other injuries) and patients with single/multiple orthopaedic injuries and other injuries. The incidence of chronic pain in the latter was almost 1.5 times higher than the $32.5 \%$ found in patients with isolated injury (Urquhart et al., 2006). This suggests that studies which included polytrauma patients might overestimate the incidence of chronic musculoskelal pain.

The strength of the PROTACT study is the application of a comprehensive set of potential prognostic factors in a prospective cohort design in a relatively large population of patients with isolated musculoskeletal injuries. Pain intensity was measured at different time points. Since there is no definition of chronic pain that distinguished it mechanically from acute pain than only by time course, knowledge in pain intensity pattern over time in the period postinjury is useful to determine if the pain intensity score at 6 months follow-up was really persistent pain. While pain intensity, quality of life, depression and anxiety were measured repeatedly, the analysis focused on the prognostic factors in pre-injury and acute pain phase, since this is the time period in which there is contact between patient and caregiver and modifiable prognostic factors can be intervened. Because some pre-injury factors are collected after injury, even though patients were asked to think of these in the period before injury, one should be aware that these factors might be contaminated by the state of the patient after injury. The six prognostic factors in the PROTACT study are able to 
predict one-fifth of the pain intensity at 6 months post-injury. Although many potential prognostic factors including sociodemographic characteristics, pain, clinical, injury- or treatment-related, and psychological factors were taken into account, other potential relevant prognostic factors, such as genetic predisposition and environmental factors were beyond the scope of present study.

Despite the fact all patients received reminders and were called by telephone, the PROTACT study has a lost-to-follow-up of $45.8 \%$. By calling non-responders, reasons for non-participation were collected from 235 of the 368 non-responders $(63.9 \%)$ and the primary outcome, the pain score at 6 months post-injury, was collected from 129 patients $(35.1 \%)$. Most frequent reasons for non-participation were lack of time $(30 \%)$, received no questionnaire $(22 \%)$ and not interested anymore $(10 \%)$. It is unlikely that this influenced our results, as these are not associated with chronic pain. Of the non-responders, $42.6 \%$ had some degree of pain (NRS $\geq 1$ ) 6 months post-injury comparable to $43.9 \%$ of all 435 included patients. Furthermore, $17.8 \%$ of the non-responders had chronic pain (NRS $\geq 4$ ), somewhat higher than the percentage of $10.1 \%$ in the included patients. This percentage in non-responders could be an overestimation as these patients may not have had persistent pain throughout 6 months, which is a criterion for the definition of chronic pain in the included patients. However, the incidence of chronic pain in the PROTACT study might be underestimated, because age of the non-responders was slightly higher and age is a risk factor for chronic pain. It has to be noted that all our prognostic factors had a wide range of values, e.g. from young to old patients, men and women, standard to very urgent, in other words a variety in patients was included and thus enough information was available to assess prediction models.

In the present study, we used internal validation to obtain more conservative estimates of the prognostic factors. Internal validation is helpful, but it cannot provide information about the model's performance elsewhere. Future research should continue to address the issue of generalizability of the prediction of chronic pain after isolated musculoskeletal injury by including larger samples of patients which makes external validation possible. Moreover, the present study focused only on the incidence and prognostic factors of chronic pain. The assessment of the consequences of chronic pain on physical and social function and health care utilization are relevant to determine the burden of chronic pain after musculoskeletal injury. With the global increase in health care costs, the costs of preventive interventions for chronic pain need to be carefully considered.

\section{Acknowledgements}

We gratefully acknowledge nurses and staff in the ED of Medisch Spectrum Twente, especially A. Christenhusz and M. Poessé-Vennevertloo, for their assistance, and all patients for participating in the PROTACT study.

\section{Author contributions}

J.G.J.P., C.J.M.D., M.J.I.J., M.I.G., M.M.R.V. and A.B.V.B. designed the PROTACT study. Data collection and data analyses were performed by J.G.J.P. under supervision of C.J.M.D. J.G.J.P. and C.J.M.D. drafted the manuscript. All authors have been commented on the drafts of the manuscript critically for important intellectual content, and have given final approval of the version to be published. The authors declare no conflict of interest related to the study.

\section{References}

Aaronson, N.K., Muller, M., Cohen, P.D.A., Essink-Bot, M.L., Fekkes, M., Sanderman, R., Sprangers, M.A.G., Velde, A.T., Verrips, E. (1998). Translation, validation, and norming of the Dutch language version of the SF-36 Health Survey in community and chronic disease populations. J Clin Epidemiol 51, 1055-1068.

Alishiri, G.H., Bayat, N., Ashtiani, A.F., Tavallaii, S.A., Assari, S., Moharamzad, Y. (2008). Logistic regression models for predicting physical and mental health-related quality of life in rheumatoid arthritis patients. Mod Rheumatol 18, 601-608.

Althaus, A., Hinrichs-Rocker, A., Chapman, R., Becker, O.A., Lefering, R., Simanski, C., Weber, F., Moser, K.H., Joppich, R., Trojan, S. (2012). Development of a risk index for the prediction of chronic post-surgical pain. Eur J Pain 16, 901-910.

Andrew, R., Derry, S., Taylor, R.S., Straube, S., Phillips, C.J. (2014). The costs and consequences of adequately managed chronic noncancer pain and chronic neuropathic pain. Pain Pract 14, 79-94.

Atherton, K., Wiles, N.J., Lecky, F.E., Hawes, S.J., Silman, A.J., Macfarlane, G.J., Jones, G.T. (2006). Predictors of persistent neck pain after whiplash injury. Emerg Med $J$ 23, 195-201.

Bijur, P.E., Latimer, C.T., Gallagher, E.J. (2003). Validation of a verbally administered numerical rating scale of acute pain for use in the emergency department. Acad Emerg Med 10, 390-392.

Breivik, H., Collett, B., Ventafridda, V., Cohen, R., Gallacher, D. (2006). Survey of chronic pain in Europe: Prevalence, impact on daily life, and treatment. Eur J Pain 10, 287-333.

Castillo, R.C., MacKenzie, E.J., Wegener, S.T., Bosse, M.J. (2006). Prevalence of chronic pain seven years following limb threatening lower extremity trauma. Pain 124, 321-329.

Clay, F.J., Watson, W.L., Newstead, S.V., McClure, R.J. (2012). A systematic review of early prognostic factors for persistent pain following acute orthopedic trauma. Pain Res Manag 17, 35.

Cleeland, C. (1989). Measurement of pain by subjective report. $A d v$ Pain Res Ther 12, 391-403.

Crombie, I.K., Davies, H.T.O., Macrae, W.A. (1998). Cut and thrust: Antecedent surgery and trauma among patients attending a chronic pain clinic. Pain 76, 167-171. 
Grotle, M., Brox, J.I., Glornsrod, B., Lonn, J.H., Vollestad, N.K. (2007) Prognostic factors in first-time care seekers due to acute low back pain. Eur J Pain 11, 290-298.

Gupta, A., Mehdi, A., Duwell, M., Sinha, A. (2010). Evidence-based review of the pharmacoeconomics related to the management of chronic nonmalignant pain. J Pain Palliat Care Pharmacother 24, 152-156.

Harrell, F., Lee, K.L., Mark, D.B. (1996). Tutorial in biostatistics multivariable prognostic models: Issues in developing models, evaluating assumptions and adequacy, and measuring and reducing errors. Stat Med 15, 361-387.

Holmes, A., Williamson, O., Hogg, M., Arnold, C., Prosser, A. Clements, J., Konstantatos, A., O'Donnell, M. (2010). Predictors of pain severity 3 months after serious injury. Pain Med 11, 990-1000.

Kalkman, C.J., Visser, K., Moen, J., Bonsel, G.J., Grobbee, D.E., Moons, K.G.M. (2003). Preoperative prediction of severe postoperative pain. Pain 105, 415-423.

Katz, J., Poleshuck, E.L., Andrus, C.H., Hogan, L.A., Jung, B.F., Kulick, D.I., Dworkin, R.H. (2005). Risk factors for acute pain and its persistence following breast cancer surgery. Pain 119, 16-25.

Keefe, F.J., Rumble, M.E., Scipio, C.D., Giordano, L.A., Perri, L.M. (2004). Psychological aspects of persistent pain: Current state of the science. J Pain 5, 195-211.

Kehlet, H., Jensen, T.S., Woolf, C.J. (2006). Persistent postsurgical pain: Risk factors and prevention. Lancet 367, 1618-1625.

Kelly, A.-M., Brumby, C., Barnes, C. (2005). Nurse-initiated, titrated intravenous opioid analgesia reduces time to analgesia for selected painful conditions. CJEM 7, 149-154.

Kyranou, M., Puntillo, K. (2012). The transition from acute to chronic pain: Might intensive care unit patients be at risk? Ann Intensive Care $2,1-11$.

Lempa, M., Koch, G., Neugebauer, E., Köhler, L., Troidl, H. (2000). How much pain is tolerable? Target expectations of surgical patients for pain therapy. Chirurg 71, 1263-1269.

Merskey, H., Albe-Fessard, D., Bonica, J. (1979). International Association for the Study of Pain. Pain terms: A list with definitions and notes on usage. Pain 6, 249-252.

Miller, R.P., Kori, S.H. and Todd, D.D. (1991). The Tampa Scale. Unpublished report. (Tampa, FL).

Mkandawire, N.C., Boot, D.A., Braithwaite, I.J., Patterson, M. (2002). Musculoskeletal recovery 5 years after severe injury: Long term problems are common. Injury 33, 111-115.

Mohan, H., Ryan, J., Whelan, B., Wakai, A. (2010). The end of the line? The Visual Analogue Scale and Verbal Numerical Rating Scale as pain assessment tools in the emergency department. Emerg Med $J$ 27, 372-375.

Moore, C.M., Leonardi-Bee, J. (2008). The prevalence of pain and disability one year post fracture of the distal radius in a UK population: A cross sectional survey. BMC Musculoskelet Disord 9, 129-139.

Motov, S.M., Khan, A.N. (2009). Problems and barriers of pain management in the emergency department: Are we ever going to get better? J Pain Res 2, 5.

Mounce, C., Keogh, E., Eccleston, C. (2010). A principal components analysis of negative affect-related constructs relevant to pain: Evidence for a three component structure. J Pain 11, 710-717.

Nederhand, M.J., Ijzerman, M.J., Hermens, H.J., Turk, D.C., Zilvold, G. (2004). Predictive value of fear avoidance in developing chronic neck pain disability: Consequences for clinical decision making. Arch Phys Med Rehabil 85, 496-501.

Pallant, J.F., Bailey, C.M. (2005). Assessment of the structure of the Hospital Anxiety and Depression Scale in musculoskeletal patients. Health Qual Life Outcomes 3, 82.

Quartana, P.J., Campbell, C.M., Edwards, R.R. (2009). Pain catastrophizing: A critical review. Expert Rev Neurother 9, 745-758.

Rivara, F.P., MacKenzie, E.J., Jurkovich, G.J., Nathens, A.B., Wang, J., Scharfstein, D.O. (2008). Prevalence of pain in patients 1 year after major trauma. Arch Surg 143, 282-287.

Royston, P., Moons, K.G., Altman, D.G., Vergouwe, Y. (2009). Prognosis and prognostic research: Developing a prognostic model. BMJ 338, b604.
Salovey, P., Seiber, W., Smith, A., Turk, D., Jobe, J., Willis, G. (1992). Reporting chronic pain episodes on health surveys (Washington, DC: US Department of Health and Human Services, Public Health Service, Centers for Disease Control, National Center for Health Statistics).

Sauerbrei, W. (1999). The use of resampling methods to simplify regression models in medical statistics. J R Stat Soc Ser C Appl Stat 48, 313-329.

Scott, W., Wideman, T., Sullivan, M. (2013). Clinically meaningful scores on pain catastrophizing before and after multidisciplinary rehabilitation: A prospective study of individuals with subacute pain after whiplash injury. Clin J Pain 30(3), 183-190.

Seguin, D. (2004). A nurse-initiated pain management advanced triage protocol for ED patients with an extremity injury at a level I trauma center. J Emerg Nurs 30, 330-335.

Shipton, E. (2011). The transition from acute to chronic post surgical pain. Anaesth Intens Care 39, 824-836.

Singer, A.J., Kowalska, A., Thode, H.C. (2001). Ability of patients to accurately recall the severity of acute painful events. Acad Emerg Med 8, 292-295.

Sleed, M., Eccleston, C., Beecham, J., Knapp, M., Jordan, A. (2005). The economic impact of chronic pain in adolescence: Methodological considerations and a preliminary costs-of-illness study. Pain 119, 183-190

Spinhoven, P., Ormel, J., Sloekers, P.P.A., Kempen, G., Speckens, A.E.M., VanHemert, A.M. (1997). A validation study of the Hospital Anxiety and Depression Scale (HADS) in different groups of Dutch subjects. Psychol Med 27, 363-370.

Sterner, Y., Toolanen, G., Gerdle, B., Hildingsson, T. (2003). The incidence of whiplash trauma and the effects of different factors on recovery. J Spinal Disord Tech 16, 195-199.

Sullivan, M.J., Thorn, B., Haythornthwaite, J.A., Keefe, F., Martin, M., Bradley, L.A., Lefebvre, J.C. (2001). Theoretical perspectives on the relation between catastrophizing and pain. Clin J Pain 17, 52-64.

Tan, G., Jensen, M.P., Thornby, J.I., Shanti, B.F. (2004). Validation of the Brief Pain Inventory for chronic nonmalignant pain. J Pain 5 , 133-137

Urquhart, D.M., Williamson, O.D., Gabbe, B.J., Cicuttini, F.M., Cameron, P.A., Richardson, M.D., Edwards, E.R. (2006). Outcomes of patients with orthopaedic trauma admitted to level 1 trauma centres. ANZ J Surg 76, 600-606.

Van Damme, S., Crombez, G., Bijttebier, P., Goubert, L., Van Houdenhove, B. (2002). A confirmatory factor analysis of the Pain Catastrophizing Scale: Invariant factor structure across clinical and non-clinical populations. Pain 96, 319-324.

VanDenKerkhof, E.G., Peters, M.L., Bruce, J. (2013). Chronic pain after surgery: Time for standardization? A framework to establish core risk factor and outcome domains for epidemiological studies. Clin J Pain $29,2-8$.

Vlaeyen, J.W.S., Kole-Snijders, A.M.J., Boeren, R.G.B., van Eek, H. (1995). Fear of movement/(re)injury in chronic low back pain and its relation to behavioral performance. Pain 62, 363-372.

Walton, D.M., MacDermid, J.C., Giorgianni, A.A., Mascarenhas, J.C., West, S.C., Zammit, C.A. (2013). Risk factors for persistent problems following acute whiplash injury: Update of a systematic review and meta-analysis. J Orthop Sports Phys Ther 43, 31-43.

Ware, J.E. Jr, Sherbourne, C.D. (1992). The MOS 36-item short-form health survey (SF-36). I. Conceptual framework and item selection. Med Care 30, 473-483.

Ware, J.E., Kosinski, M., Keller, S.D. (1994). SF-36 physical and mental summary scales: A user's manual (Boston, MA: The Health Institute, New England Medical Center).

Weijenborg, P.T.M., Gardien, K., Toorenvliet, B.R., Merkus, J.W.S., ter Kuile, M.M. (2010). Acute abdominal pain in women at an emergency department: Predictors of chronicity. Eur J Pain 14, 183-188.

Williamson, O.D., Gabbe, B.J., Cameron, P.A., Edwards, E.R., Richardson, M.D.; Victorian Orthopaedic Trauma, O. (2009). Predictors of moderate or severe pain 6 months after orthopaedic injury: A prospective cohort study. J Orthop Trauma 23, 139-144. 